\title{
p16 as a prognostic factor for the response to induction chemotherapy in advanced hypopharyngeal squamous cell carcinoma
}

\author{
JOON KYOO LEE ${ }^{1}$, KYUNG-HWA LEE ${ }^{2}$, SUN-AE KIM ${ }^{1}$, SUN SEOG KWEON ${ }^{3}$, \\ SANG-HEE CHO ${ }^{4}$, HYUN-JEONG SHIM ${ }^{4}$, WOO-KYUN BAE ${ }^{4}$, IK-JOO CHUNG $^{4}$, \\ WOONG-KI CHUNG ${ }^{5}$, TAE MI YOON ${ }^{1}$, SANG CHUL LIM ${ }^{1}$ and DONG HOON LEE ${ }^{1}$ \\ Departments of ${ }^{1}$ Otolaryngology-Head and Neck Surgery, ${ }^{2}$ Pathology, ${ }^{3}$ Preventive Medicine, \\ ${ }^{4}$ Internal Medicine and ${ }^{5}$ Radiation Oncology, Chonnam National University Medical School and \\ Chonnam National University Hwasun Hospital, Hwasun, Jeonnam 519-809, Republic of Korea
}

Received January 20, 2016; Accepted June 2, 2017

DOI: $10.3892 / \mathrm{ol} .2018 .8138$

\begin{abstract}
The present study was conducted to investigate the prognostic significance of p16 (also known as cyclin-dependent kinase inhibitor 2A) in the treatment of induction chemoradiotherapy for advanced hypopharyngeal squamous cell carcinoma (HPSCC). Patients who were treated with at least two cycles of induction chemotherapy followed by concurrent chemoradiotherapy for locally advanced HPSCC were reviewed in the study. The staining results were analyzed to examine the association between the chemotherapy response and the survival outcome. A total of 45 patients were enrolled for the present study; the majority had received induction chemotherapy with docetaxel, cisplatin, and 5-FU. Following induction chemotherapy, 17 patients $(37.8 \%)$ exhibited a complete response and 28 patients $(62.2 \%)$ exhibited a partial response. There were 11 patients $(24.4 \%)$ with p16-positive immunohistochemical stains and 30 patients $(66.7 \%)$ with p53-positive immunohistochemical stains. There was no significant difference in chemotherapy response, overall survival, or progression-free survival time between groups with p16-positive and p16-negative stains. Low p53 expression and chemotherapy response were not associated with each other. High p16 expression did not correlate with low p53 expression. In this study, p16 was not determined to predict the chemotherapy response for HPSCC. High p16 expression did not correlate with survival incidence for patients with HPSCC.
\end{abstract}

Correspondence to: Dr Dong Hoon Lee, Department of Otolaryngology-Head and Neck Surgery, Chonnam National University Medical School and Chonnam National University Hwasun Hospital, 160 Ilsimri, Hwasun, Jeonnam 519-809, Republic of Korea E-mail: leen31@hanmail.net

Key words: hypopharyngeal cancer, squamous cell carcinoma, p16, $\mathrm{p} 53$, induction chemotherapy, prognostic significance

\section{Introduction}

Patients with human papillomavirus (HPV)-associated oropharyngeal cancer (OPC) exhibit an improved prognosis in terms of response and survival (1). High-risk HPV types, particularly 16 and 18, shown serve a central role in the development of head and neck cancer $(2,3)$. It has been identified that $\sim 26 \%$ of head and neck squamous cell carcinoma cases and $36 \%$ of oropharyngeal squamous cell carcinomas are HPV-positive; additionally, the relative proportion of HPV-positive head and neck squamous cell carcinomas has been increasing over the past 20 years (2).

p16, also known as cyclin-dependent kinase inhibitor 2A, has been postulated as a surrogate marker for HPV (3). The $\mathrm{p} 16 / \mathrm{Rb} /$ cyclin-D1 pathway is a key regulator of the cell cycle. The p16 protein inhibits cdk4- and cdk- 6 cyclin D complexes, and prevents $\mathrm{Rb}$ phosphorylation. p16 protein is inactivated by the HPV viral oncoprotein E7 (2).

However, there is controversy regarding the prognostic role of HPV in hypopharyngeal cancer. Certain studies have advocated for it (4), whereas others have reported that it does not have prognostic value (5). Therefore, the present study investigated the prognostic value of p16 expression status with respect to the response to induction chemotherapy for advanced hypopharyngeal squamous cell carcinoma (HPSCC), which has long been the established treatment regimen at Chonnam National University Medical School and Hwasun Hospital (Hwasun, South Korea) (6-8). The present study also investigated tumor protein P53 (hereafter p53) expression status, which has been reported to predict the treatment response for advanced cancer $(9,10)$.

\section{Materials and methods}

Patients and tumor specimens. A total of 45 patients over the age of 18 years (43 male, 2 female; age range, 46-82 years; mean, 63.0 years) that had been diagnosed with locally advanced HPSCC between January 2004 and December 2013 (for 10 years) were retrospectively reviewed. Inclusion criteria 
were the following: Biopsy-confirmed SCC arising in the hypopharynx; stage III or IV cancer; treatment with at least two cycles of induction chemotherapy followed by concurrent chemoradiation therapy and paraffin-embedded tumor tissue available at diagnosis. All patients were staged again according to the seventh edition of the American Joint Committee on Cancer staging system (11).

Induction chemotherapy was performed with docetaxel $\left(70 \mathrm{mg} / \mathrm{m}^{2}\right.$ on day 1$)$, cisplatin $\left(75 \mathrm{mg} / \mathrm{m}^{2}\right.$ on day 1$)$, and fluorouracil (5-FU; $1,000 \mathrm{mg} / \mathrm{m}^{2}$ on days $1-4$ ) repeated every 3 weeks for up to three cycles. The treatment was followed by cisplatin-based concurrent chemoradiation therapy (CCRT). Radiotherapy was started within 4 weeks of the completion of induction chemotherapy, and the primary tumor and neck area were involved in the treatment field. Cisplatin $\left(100 \mathrm{mg} / \mathrm{m}^{2}\right.$, 1 day schedule) was administered on the same day of the start of the radiation and repeated every 3 weeks, depending on creatinine clearance.

The clinicopathological characteristics of patients, including age, sex, history of smoking or alcohol consumption, tumor location, stage, differentiation, Karnofsky performance status, response to treatment, radiation dose, radiation type, progression-free survival (PFS) and overall survival (OS) time and follow-up information were all obtained from hospital records. Patient characteristics are summarized in Table I.

The response evaluation was based on the Response Evaluation Criteria in Solid Tumor (RECIST 1.1) (12), which was assessed by physical examination, laryngoscopy and imaging studies. A partial response (PR) was defined as a $>50 \%$ decrease in tumor size and a complete response (CR) was defined as no visible or palpable disease. Stable disease (SD) was defined as stationary or progressive disease. The current study was approved by the Institutional Review Board of Chonnam National University Hwasun Hospital (Hwasun, South Korea).

Immunohistochemistry. Automated immunohistochemistry was performed using the Bond-Max system (Leica Biosystems, Ltd., Newcastle, UK). Tissue sections of $2 \mu \mathrm{m}$ were cut from each paraffin block and dried for $1 \mathrm{~h}$ at $60^{\circ} \mathrm{C}$. Slides were then covered with Bond Universal Covertiles and placed into the Bond-Max instrument (Leica Biosystems, Ltd.). All steps were performed according to the manufacturer's protocol in the following order: i) Deparaffinization using Bond Dewax Solution (Leica Biosystems, Ltd.) at $72^{\circ} \mathrm{C}$ for $30 \mathrm{~min}$; ii) heat-induced epitope retrieval using Bond Epitope Retrieval Solution 1 (Leica Biosystems, Ltd.) for $20 \mathrm{~min}$ at $100^{\circ} \mathrm{C}$; iii) peroxide block placement on the slides for $5 \mathrm{~min}$ at ambient temperature; iv) incubation with anti-p16 (1:50 dilution; cat no. G175-407; BD Pharmingen; BD Biosciences, San Jose, CA, USA) or anti-p53 (1:1,200 dilution; cat no. DO-7; Dako; Agilent Technologies GmbH, Waldbronn, Germany) primary antibody for $15 \mathrm{~min}$ at ambient temperature; v) incubation with Post Primary reagent (Leica Biosystems, Ltd.) for $8 \mathrm{~min}$ at ambient temperature, followed by washing using Bond Wash solution (Leica Biosystems, Ltd.) for $6 \mathrm{~min}$; vi) Bond ${ }^{\mathrm{TM}}$ Polymer Refine Detection (ready-to-use dilution; cat no. DS9800; Leica Biosystems, Ltd.) placement on the slides for 8 min at ambient temperature, followed by washing using Bond Wash (Leica Biosystems, Ltd.) and distilled water for 4 min; vii) color development with 3,3'-diaminobenzidine tetrahydrochloride chromogen for $10 \mathrm{~min}$ at ambient temperature; and viii) hematoxylin counterstaining for $5 \mathrm{~min}$ at ambient temperature, followed by mounting of the slides. Normal human serum served as a negative control. Stained tissues were viewed and images captured using a light microscope under five fields in each sample (magnification, x100).

Evaluation of immunohistochemical staining. The staining results for p16 and p53 were statistically examined in several ways. Fist, the evaluation of all staining was performed as a blind assessment by one pathologist who was a specialist in the head and neck region. Staining intensity for p16 was scored between 0 and 3 ( 0 , negative; 1 , weakly positive; 2 , moderately positive; 3 , strongly positive). The percentage of the staining area was graded on a scale with five grades: No staining, 0 ; $<25 \%$ staining, $1 ; 25-49 \%, 2 ; 50-74 \%, 3$; and $\geq 75 \%$, 4 . The staining index for p16 was calculated as the multiplication of the staining intensity and the staining area scores. Tumors were categorized as high (staining index $\geq 6$ ) or low (staining index $<6$ ). Staining intensity $>3$ was evaluated as positive. For p53, the group was divided into two groups: High (staining area $\geq 10 \%$ ), and low (staining area $<10 \%$ ).

Statistical analysis. The association between immunohistochemical staining and clinicopathological parameters was examined using the $\chi^{2}$ test and Fisher's exact test. Survival curves were calculated using the Kaplan-Meier method, and a comparison of the curves was performed using the log-rank test. PFS was calculated from the start date of chemotherapy to the date of recurrence or progression and OS was measured from the start date of treatment to the date of mortality or date last seen. Variables were incorporated in the univariate or multivariate Cox hazard regression model. SPSS version 20.0 (IBM Corp., Armonk, NY, USA) was used for statistical analyses. $\mathrm{P}<0.05$ was considered to indicate a statistically significant difference.

\section{Results}

Patient characteristics. A total of 45 patients who had finished at least two cycles of induction chemotherapy and CCRT were enrolled in the present study. Of these patients, $35(77.8 \%)$ received docetaxel, cisplatin and 5-FU for induction chemotherapy, and $10(22.2 \%)$ received cisplatin and 5-FU for induction chemotherapy. The majority of the patients underwent three cycles of induction chemotherapy (40 patients, $88.9 \%$ ) and the remaining five patients underwent two cycles of induction chemotherapy. Following induction chemotherapy, 17 patients (37.8\%) exhibited CR and 28 patients $(62.2 \%)$ exhibited PR. The treatment was followed by cisplatin-based CCRT. The CR rate was $82.2 \%$ (37 patients) and all others were 17.8\% (8 patients) following completion of all treatment.

Expression of p16 and p53. Staining for p16 was observed in the nucleus and cytoplasm of the tumor cells and occasionally in the stroma (Fig. 1). There were 11 patients (24.4\%) with p16-positive tumor cells. The correlation between p16 expression and clinicopathological parameters is presented 
Table I. Patient clinicopathological characteristics.

\begin{tabular}{|c|c|c|c|c|}
\hline \multirow[b]{2}{*}{ Patient demographics } & \multirow[b]{2}{*}{ Total, n (\%) } & \multicolumn{3}{|c|}{ p16 expression, $n$} \\
\hline & & Positive (\%) & Negative $(\%)$ & P-value \\
\hline Age, years & & & & 0.533 \\
\hline$\geq 70$ & $14(31.1)$ & $3(27.3)$ & $11(32.4)$ & \\
\hline$<70$ & $31(68.9)$ & $8(72.7)$ & $23(67.6)$ & \\
\hline Sex & & & & 0.056 \\
\hline Male & $43(95.6)$ & $9(81.8)$ & $34(100.0)$ & \\
\hline Female & $2(4.4)$ & $2(18.2)$ & $0(0.0)$ & \\
\hline Smoking & & & & 0.266 \\
\hline Never & $15(33.3)$ & $5(45.5)$ & $10(29.4)$ & \\
\hline Ex/current & $30(66.7)$ & $6(54.5)$ & $24(70.6)$ & \\
\hline Alcohol & & & & 0.266 \\
\hline Never/social & $15(33.3)$ & $5(45.5)$ & $10(29.4)$ & \\
\hline Heavy & $30(66.7)$ & $6(54.5)$ & $24(70.6)$ & \\
\hline Anatomical site & & & & 0.038 \\
\hline Pyriform sinus & $35(77.8)$ & $7(63.6)$ & $28(82.4)$ & \\
\hline Posterior wall & $8(17.8)$ & $2(18.2)$ & $6(17.6)$ & \\
\hline Postcricoid area & $2(4.4)$ & $2(18.2)$ & $0(0.0)$ & \\
\hline Clinical stage & & & & 0.153 \\
\hline III & $16(35.6)$ & $2(18.2)$ & $14(41.2)$ & \\
\hline IV & $29(64.4)$ & $9(81.8)$ & $20(58.8)$ & \\
\hline T stage & & & & 0.014 \\
\hline $\mathrm{T} 1-2$ & $23(51.1)$ & $2(18.2)$ & $21(61.8)$ & \\
\hline $\mathrm{T} 3-4$ & $22(48.9)$ & $9(81.8)$ & $13(38.2)$ & \\
\hline $\mathrm{N}$ stage & & & & 0.396 \\
\hline N0-1 & $20(44.4)$ & $4(36.4)$ & $16(47.1)$ & \\
\hline N2-3 & $25(55.6)$ & $7(63.6)$ & $18(52.9)$ & \\
\hline Differentiation & & & & 0.700 \\
\hline Well & $11(24.4)$ & $4(36.4)$ & $7(20.6)$ & \\
\hline Moderate & $11(24.4)$ & $2(18.2)$ & $9(26.5)$ & \\
\hline Poor & $7(15.6)$ & $2(18.2)$ & $5(14.7)$ & \\
\hline NA & $16(35.6)$ & $3(27.3)$ & $13(38.2)$ & \\
\hline PS & & & & 0.014 \\
\hline 0 & $29(64.4)$ & $8(72.7)$ & $21(61.8)$ & \\
\hline 1 & $14(31.1)$ & $1(9.1)$ & $13(38.2)$ & \\
\hline 2 & $2(4.4)$ & $2(18.2)$ & $0(0.0)$ & \\
\hline Induction response 1 & & & & 0.398 \\
\hline CR & $17(37.8)$ & $5(45.5)$ & $12(35.3)$ & \\
\hline Non-CR & $28(62.2)$ & $6(54.5)$ & $22(64.7)$ & \\
\hline Induction response 2 & & & & 0.689 \\
\hline PR, CR & $41(91.1)$ & $10(90.9)$ & $31(91.2)$ & \\
\hline Non-PR or CR & $4(8.9)$ & $1(9.1)$ & $3(8.8)$ & \\
\hline CRT response & & & & 0.359 \\
\hline CR & $37(82.2)$ & $10(90.9)$ & $27(79.4)$ & \\
\hline Non-CR & $8(17.8)$ & $1(9.1)$ & $7(20.6)$ & \\
\hline RT dose, cGy & & & & 0.533 \\
\hline$\geq 6,500$ & $31(68.9)$ & $8(72.7)$ & $23(67.6)$ & \\
\hline$<6,500$ & $14(31.1)$ & $3(27.3)$ & $11(32.4)$ & \\
\hline
\end{tabular}


Table I. Continued.

\begin{tabular}{lcccc}
\hline & & \multicolumn{3}{c}{ p16 expression, $\mathrm{n}$} \\
\cline { 4 - 4 } Patient demographics & Total, $\mathrm{n}(\%)$ & Positive $(\%)$ & Negative (\%) & P-value \\
\hline RT type & & & & 0.128 \\
3D-CRT & $33(73.3)$ & $10(90.9)$ & $23(67.6)$ & \\
Others & $12(26.7)$ & $1(9.1)$ & $11(32.4)$ & \\
\hline
\end{tabular}

PS, performance status; induction response, induction chemotherapy response; CR, complete response; PR, partial response; CRT, chemotherapy and radiation therapy; 3D-CRT, three-dimensional conformal radiation therapy.

Table II. Expression of p53 stratified by p16 status.

\begin{tabular}{lllll}
\hline & \multicolumn{3}{c}{ p16 status, $\mathrm{n}$} \\
\cline { 3 - 5 } $\begin{array}{l}\text { p53 } \\
\text { expression }\end{array}$ & Total, n (\%) & Positive (\%) & Negative (\%) & P-value \\
\hline p53 & & & 0.198 \\
Low & $15(33.3)$ & $2(18.2)$ & $13(38.2)$ & \\
High & $30(66.7)$ & $9(81.8)$ & $21(61.8)$ & \\
\hline
\end{tabular}

p16, cyclin-dependent kinase inhibitor 2A; p53, tumor protein p53.

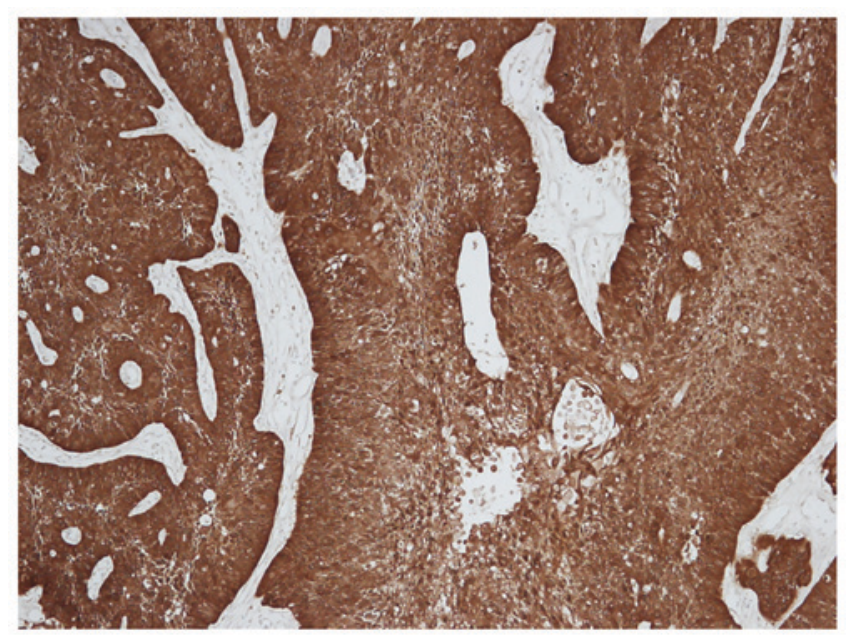

Figure 1. Strong p16 positive staining was observed in the nucleus and cytoplasm of the tumor cells, with occasional staining in the stroma (magnification, x100). p16, cyclin-dependent kinase inhibitor 2A.

in Table I. No significant differences were identified between the two types of responses of induction chemotherapy (CR vs. non-CR; PR and CR vs. other) according to p16 status. No significant differences were identified in the response following all treatments (chemotherapy and radiation therapy) between groups with p16-positive and p16-negative staining.

p53 frequently stained the nucleus of tumor cells and was occasionally observed in the cytoplasm (Fig. 2). There were 30 patients $(66.7 \%)$ with high expression levels of $\mathrm{p} 53$. The associations between p16-positivity and low p53, and between

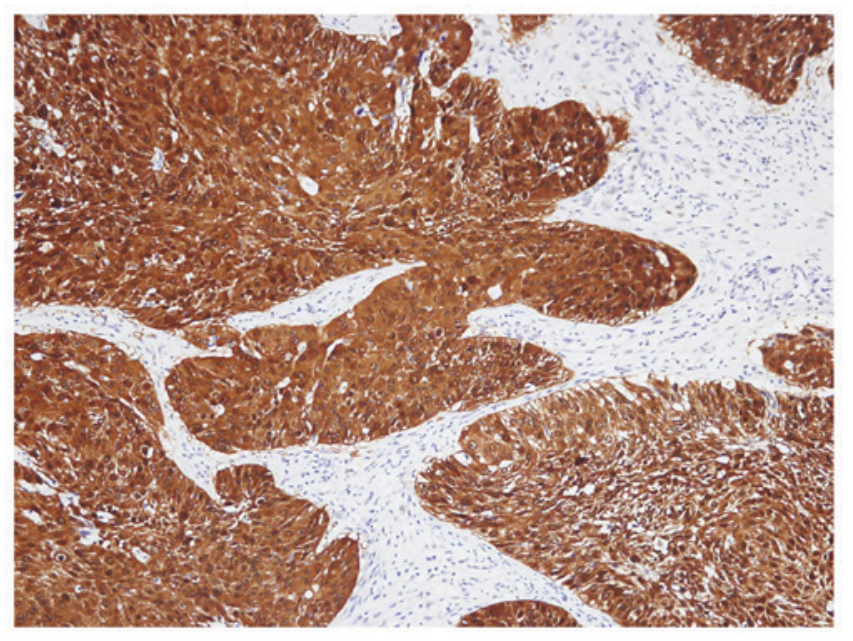

Figure 2. Strong p53 positive staining was presented in the nucleus of the tumor cells, including in the cytoplasm (magnification, x100). p53, tumor protein $\mathrm{p} 53$.

p16-negativity and high p53 were analyzed; however, no significant difference was identified $(\mathrm{P}>0.05$; Table II). No association between low p53 expression and chemotherapy response was observed (data not shown).

Survival according to pl6 status. A univariate analysis for PFS and OS time was performed. A good response to induction chemotherapy (PR and CR vs. other) was demonstrated to significantly decrease the risk of mortality $(\mathrm{P}<0.001$; Table III).

There was no significant difference in the survival (PFS or OS) times between p16-positive and p16-negative staining groups ( $\mathrm{P}>0.05$; Table III and Fig. 3). Furthermore, according to multivariate analysis, p16 did not alter the PFS or OS time ( $P>0.05$; Table IV).

\section{Discussion}

The present study examined the degree to which HPV may be involved in hypopharyngeal cancer. For oropharyngeal cancer, an increased trend of occurrence in young adults and non-smokers was previously reported, and changes in environmental risk factors, including changes in smoking patterns and an increase in oral HPV infections, have been postulated (13-15). However, the present study identified no association between 
Table III. Univariate survival analysis.

\begin{tabular}{|c|c|c|c|c|}
\hline Variable & PFS, OR (95\% CI) & P-value & OS, OR (95\% CI) & P-value \\
\hline Age & $0.704(0.311-1.594)$ & 0.400 & $0.647(0.277-1.510)$ & 0.314 \\
\hline Gender & $1.671(0.225-12.400)$ & 0.616 & $22.289(0.015-33,910.767)$ & 0.406 \\
\hline Smoking & $1.322(0.598-2.920)$ & 0.490 & $1.427(0.630-3.232)$ & 0.395 \\
\hline Alcohol & $1.187(0.529-2.666)$ & 0.678 & $1.339(0.577-3.108)$ & 0.497 \\
\hline \multicolumn{5}{|l|}{ Anatomic site } \\
\hline Pyriform sinus & & 0.522 & & 0.460 \\
\hline Posterior wall & $1.438(0.532-3.887)$ & 0.474 & $1.568(0.578-4.256)$ & 0.377 \\
\hline Postcricoid area & $2.058(0.474-8.940)$ & 0.336 & $2.089(0.480-9.090)$ & 0.326 \\
\hline Clinical stage & $1.418(0.629-3.196)$ & 0.400 & $1.542(0.663-3.582)$ & 0.314 \\
\hline T stage & $1.936(0.886-4.228)$ & 0.098 & $2.066(0.926-4.607)$ & 0.076 \\
\hline N stage & $1.191(0.554-2.563)$ & 0.654 & $1.273(0.581-2.789)$ & 0.546 \\
\hline \multicolumn{5}{|l|}{ Differentiation } \\
\hline Well & & 0.618 & & 0.547 \\
\hline Moderate & $1.280(0.386-4.237)$ & 0.686 & $1.609(0.449-5.765)$ & 0.465 \\
\hline Poor & $2.087(0.624-6.983)$ & 0.232 & $2.500(0.694-9.006)$ & 0.161 \\
\hline NA & $1.129(0.382-3.335)$ & 0.827 & $1.424(0.442-4.587)$ & 0.553 \\
\hline \multicolumn{5}{|l|}{ PS } \\
\hline 0 & & 0.874 & & 0.828 \\
\hline 1 & $1.105(0.490-2.491)$ & 0.810 & $1.186(0.521-2.698)$ & 0.684 \\
\hline 2 & $0.647(0.085-4.920)$ & 0.674 & $0.664(0.087-5.058)$ & 0.692 \\
\hline Induction response 1 & $0.570(0.246-1.320)$ & 0.189 & $0.587(0.252-1.368)$ & 0.217 \\
\hline Induction response 2 & $0.082(0.023-0.296)$ & $<0.001$ & $0.082(0.023-0.296)$ & $<0.001$ \\
\hline CRT response & $0.517(0.204-1.310)$ & 0.164 & $0.472(0.186-1.201)$ & 0.115 \\
\hline RT dose & $1.165(0.491-2.765)$ & 0.729 & $1.088(0.456-2.598)$ & 0.848 \\
\hline RT type & $2.321(0.838-6.432)$ & 0.105 & $2.065(0.745-5.727)$ & 0.163 \\
\hline p16 status & $1.128(0.468-2.720)$ & 0.788 & $0.938(0.371-2.373)$ & 0.892 \\
\hline p53 status & $1.649(0.696-3.911)$ & 0.256 & $1.530(0.642-3.644)$ & 0.337 \\
\hline
\end{tabular}

PFS, progression-free survival; OS, overall survival; OR, odds ratio; PS, performance status; induction response, induction chemotherapy response; CR, complete response; PR, partial response; CRT, chemotherapy and radiation therapy.
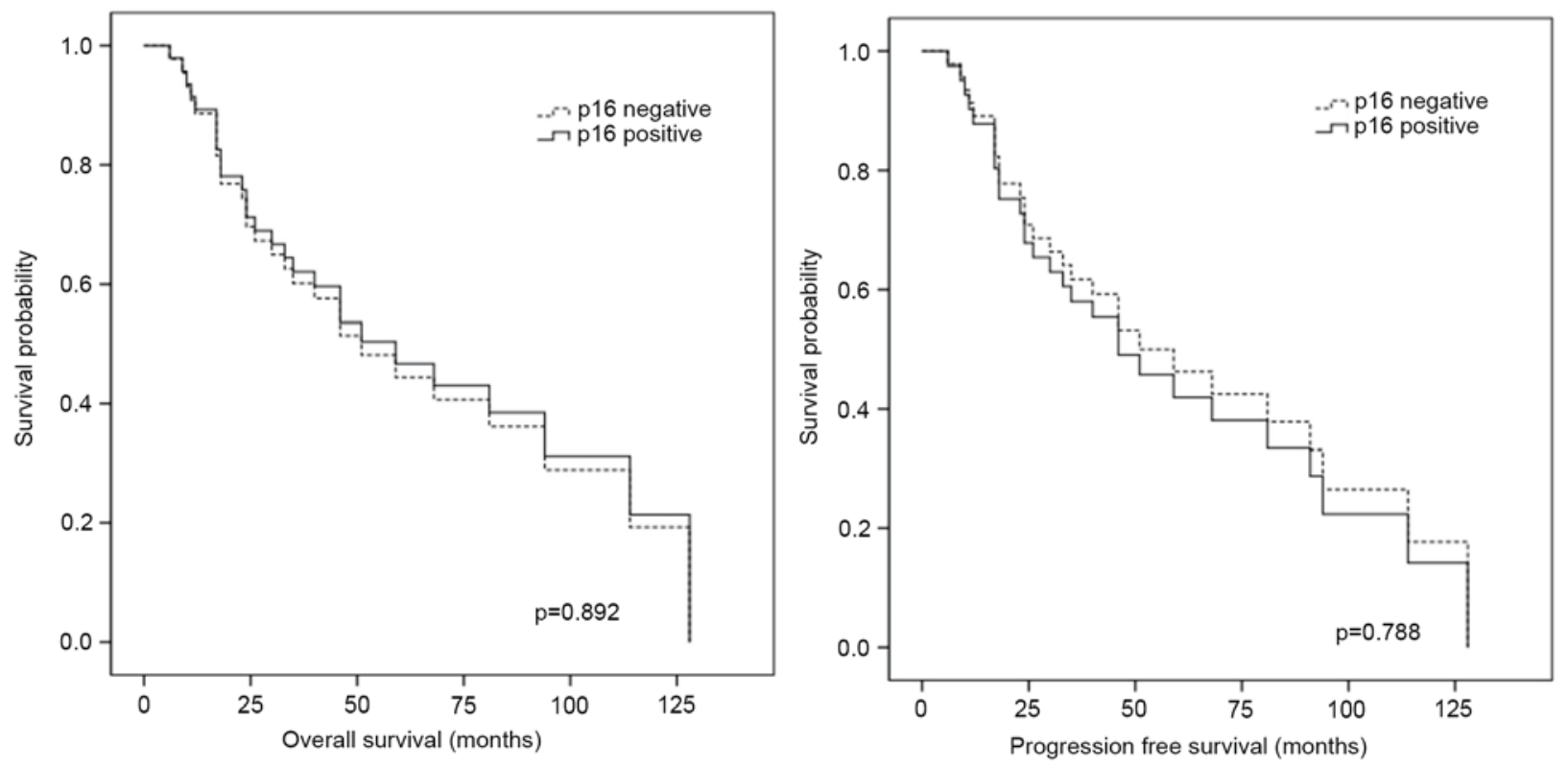

Figure 3. Univariate analysis of survival revealed no difference between p16 status and survival. p16, cyclin-dependent kinase inhibitor 2A. 
Table IV. Multivariate survival analysis.

\begin{tabular}{|c|c|c|c|c|}
\hline Variable & PFS, OR (95\% CI) & P-value & OS, OR (95\% CI) & P-value \\
\hline p16 status & $0.828(0.224-3.059)$ & 0.777 & $0.601(0.153-2.366)$ & 0.466 \\
\hline p53 status & $1.531(0.554-4.232)$ & 0.412 & $1.342(0.476-3.787)$ & 0.578 \\
\hline Age & $1.051(0.371-2.982)$ & 0.925 & $0.793(0.252-2.499)$ & 0.692 \\
\hline \multicolumn{5}{|l|}{ Differentiation } \\
\hline Well & & 0.709 & & 0.648 \\
\hline Moderate & $1.053(0.225-4.922)$ & 0.948 & $1.243(0.241-6.423)$ & 0.795 \\
\hline Poorly & $2.318(0.428-12.538)$ & 0.329 & $2.820(0.482-16.495)$ & 0.250 \\
\hline NA & $1.095(0.265-4.530)$ & 0.901 & $1.296(0.289-5.813)$ & 0.735 \\
\hline \multicolumn{5}{|l|}{ Anatomic site } \\
\hline Pyriform sinus & & 0.208 & & 0.173 \\
\hline Posterior wall & $2.425(0.629-9.355)$ & 0.198 & $2.474(0.643-9.527)$ & 0.188 \\
\hline Postcricoid area & $6.111(0.523-71.447)$ & 0.149 & $7.655(0.583-100.499)$ & 0.121 \\
\hline T stage & $1.942(0.716-5.264)$ & 0.192 & $2.340(0.817-6.701)$ & 0.113 \\
\hline $\mathrm{N}$ stage & $1.337(0.494-3.624)$ & 0.568 & $1.670(0.572-4.877)$ & 0.348 \\
\hline RT dose & $1.870(0.518-6.752)$ & 0.339 & $1.457(0.394-5.396)$ & 0.573 \\
\hline RT type & $2.644(0.792-8.826)$ & 0.114 & $2.080(0.611-7.077)$ & 0.241 \\
\hline \multicolumn{5}{|l|}{ PS } \\
\hline 0 & & 0.390 & & 0.464 \\
\hline 1 & $1.371(0.498-3.771)$ & 0.541 & $1.402(0.512-3.839)$ & 0.511 \\
\hline 2 & $0.136(0.006-2.998)$ & 0.206 & $0.170(0.007-4.229)$ & 0.280 \\
\hline
\end{tabular}

PFS, progression-free survival; OS, overall survival; OR, odds ratio; PS, performance status; p16, cyclin-dependent kinase inhibitor 2A; p53, tumor protein $\mathrm{p} 53$; RT, radiotherapy.

HPV infection and age or smoking history in hypopharyngeal cancer. The present study included 14 patients $<60$ years of age (although only one patient was $<50$ years old) with HPSCC in the current study, of whom only 3 exhibited p16-positive tumors (data not shown). Age, smoking status or alcohol-drinking status did not correlate with p16-positive expression. The present study revealed that 11 patients $(24.4 \%)$ were positive for p16 expression in advanced HPSCC, which is slightly higher compared with other reports $(4,16,17)$. However, p16 expression status did not predict chemoradiotherapy response or survival rate in the present study. There remains controversy regarding the role of p16 in the prognosis of HPSCC. Certain studies have demonstrated that patients with HPV tend to have improved prognoses $(16,18)$, although others have reported the opposite $(5,19)$.

p53 has been reported to be a prognostic factor and predictive marker of the response to chemotherapy in various types of head and neck cancer, including oropharyngeal carcinoma $(9,20,21)$. In HPV-associated oropharyngeal cancer, p53 expression is low owing to HPV E6 protein activity, which targets p53 for ubiquitination and degradation (22). This can preserve the apoptotic function of p53 and thus enable radiation-induced apoptosis (23). Therefore, the present study also investigated p53 expression in HPSCC; 30 patients (66.7\%) exhibited high p53 expression levels. However, there was no association between p16-positivity and low p53 expression. Furthermore, low p53 expression was not associated with chemotherapy response in the present study.

The staining results for p16 and p53 were examined for staining intensity and percentage of staining. However, despite the use of these analytic methods, no significance was identified between p16 or p53 expression and clinicopathological parameters, treatment response, or survival. A limitation of the present study was the small sample size; thus, additional studies with more cases are warranted.

In the present study, p16 expression status was not identified to predict the response to chemotherapy in patients with HPSCC. Furthermore, no association between high p16 expression and the survival time of patients with HPSCC was identified.

\section{Acknowledgements}

The present study was supported by the Chonnam National University Hospital Biomedical Research Institute (grant no. HCRI 14 016-1). The abstract was presented at the AAO-HNSF Annual Meeting and OTO Expo 2015, September 27-30, 2015 (Dallas, TX, USA).

\section{References}

1. Kumar B, Cordell KG, Lee JS, Worden FP, Prince ME, Tran HH, Wolf GT, Urba SG, Chepeha DB, Teknos TN, et al: EGFR, p16, HPV titer, Bcl-xL and p53, sex, and smoking as indicators of response to therapy and survival in oropharyngeal cancer. J Clin Oncol 26: 3128-3137, 2008.

2. Geißler C, Tahtali A, Diensthuber M, Gassner D, Stöver T and Wagenblast $\mathrm{J}$ : The role of $\mathrm{p} 16$ expression as a predictive marker in HPV-positive oral SCCHN-a retrospective single-center study. Anticancer Res 33: 913-916, 2013. 
3. Sritippho T, Pongsiriwet S, Lertprasertsuke N, Buddhachat K, Sastraruji T and Iamaroon A: p16-a possible surrogate marker for high-risk human papillomaviruses in oral cancer? Asian Pac J Cancer Prev 17: 4049-4057, 2016.

4. Shaughnessy JN, Farghaly H, Wilson L, Redman R, Potts K, Bumpous J, Silverman C and Dunlap NE: HPV: A factor in organ preservation for locally advanced larynx and hypopharynx cancer? Am J Otolaryngol 35: 19-24, 2014.

5. Wilson DD, Rahimi AS, Saylor DK, Stelow EB, Jameson MJ, Shonka DC, Reibel JF, Levine PA and Read PW: p16 not a prognostic marker for hypopharyngeal squamous cell carcinoma. Arch Otolaryngol Head Neck Surg 138: 556-561, 2012.

6. Ahn JS, Cho SH, Kim OK, Lee JK, Yang DH, Kim YK, Lee JJ, Lim SC, Kim HJ, Chung WK and Chung IJ: The efficacy of an induction chemotherapy combination with docetaxel, cisplatin and 5-FU followed by concurrent chemoradiotherapy in advanced head and neck cancer. Cancer Res Treat 39: 93-98, 2007.

7. Bae WK, Hwang JE, Shim HJ, Cho SH, Lee JK, Lim SC, Chung WK and Chung IJ: Phase II study of docetaxel, cisplatin, and 5-FU induction chemotherapy followed by chemoradiotherapy in locoregionally advanced nasopharyngeal cancer. Cancer Chemother Pharmacol 65: 589-595, 2010.

8. Bae WK, Hwang JE, Shim HJ, Cho SH, Lee KH, Han HS, Song EK, Yun HJ, Cho IS, Lee JK, et al: Multicenter phase II study of weekly docetaxel, cisplatin, and S-1 (TPS) induction chemotherapy for locally advanced squamous cell cancer of the head and neck. BMC Cancer 13: 102, 2013.

9. Temam S, Flahault A, Périé S, Monceaux G, Coulet F, Callard P, Bernaudin JF, St Guily JL and Fouret P: p53 gene status as a predictor of tumor response to induction chemotherapy of patients with locoregionally advanced squamous cell carcinomas of the head and neck. J Clin Oncol 18: 385-394, 2000.

10. Bristow RG, Benchimol S and Hill RP: The p53 gene as a modifier of intrinsic radiosensitivity: Implications for radiotherapy Radiother Oncol 40: 197-223, 1996.

11. Edge SB and Compton CC: The American Joint Committee on Cancer: The 7th edition of the AJCC cancer staging manual and the future of TNM. Ann Surg Oncol 17: 1471-1474, 2010.

12. Eisenhauer EA, Therasse P, Bogaerts J, Schwartz LH, Sargent D, Ford R, Dancey J, Arbuck S, Gwyther S, Mooney M, et al: New response evaluation criteria in solid tumours: Revised RECIST guideline (version 1.1). Eur J Cancer 45: 228-247, 2009.

13. Frisch $M$, Hjalgrim $\mathrm{H}$, Jaeger $\mathrm{AB}$ and Biggar RJ: Changing patterns of tonsillar squamous cell carcinoma in the United States. Cancer Causes Control 11: 489-495, 2000.
14. Nasman A, Attner P, Hammarstedt L, Du J, Eriksson M, Giraud G, Ahrlund-Richter S, Marklund L, Romanitan M, Lindquist D, et al: Incidence of human papillomavirus (HPV) positive tonsillar carcinoma in Stockholm, Sweden: An epidemic of viral-induced carcinoma? Int J Cancer 125: 362-366, 2009.

15. Shin A, Jung YS, Jung KW, Kim K, Ryu J and Won YJ: Trends of human papillomavirus-related head and neck cancers in Korea: National cancer registry data. Laryngoscope 123: E30-E37, 2013.

16. Dalianis T, Grün N, Koch J, Vlastos A, Tertipis N, Nordfors C, Näsman A, Wendt M, Romanitan M, Bersani C, et al: Human papillomavirus DNA and p16(INK4a) expression in hypopharyngeal cancer and in relation to clinical outcome, in Stockholm, Sweden. Oral Oncol 51: 857-861, 2015.

17. Rodrigo JP, Hermsen MA, Fresno MF, Brakenhoff RH, Garcia-Velasco F, Snijders PJ, Heideman DA and García-Pedrero JM: Prevalence of human papillomavirus in laryngeal and hypopharyngeal squamous cell carcinomas in northern Spain. Cancer Epidemiol 39: 37-41, 2015.

18. Kanyilmaz G, Ekinci O, Muge A, Celik S and Ozturk F: HPV-associated p16 INK4A expression and response to therapy and survival in selected head and neck cancers. Asian Pac J Cancer Prev 16: 253-258, 2015.

19. Ang SH, Haaland B, Acharyya S, Thu MM, Krisna SS, Hwang SG, Tan PH, Ng QS, Tan DS, Tai WM, et al: Interactions between clinical factors, p16, and cyclin-D1 expression and survival outcomes in oropharyngeal and hypopharyngeal squamous cell carcinoma. Head Neck 37: 1650-1659, 2015.

20. Shinohara S, Kikuchi M, Tona R, Kanazawa Y, Kishimoto I, Harada H, Imai Y and Usami Y: Prognostic impact of p16 and p53 expression in oropharyngeal squamous cell carcinomas. Jpn J Clin Oncol 44: 232-240, 2014.

21. Kim MJ, Ki MS, Kim K, Shim HJ, Hwang JE, Bae WK, Chung IJ, Lee DH, Lee JK, Yoon TM, et al: Different protein expression associated with chemotherapy response in oropharyngeal cancer according to HPV status. BMC Cancer 14: 824, 2014.

22. Chung CH and Gillison ML: Human papillomavirus in head and neck cancer: Its role in pathogenesis and clinical implications. Clin Cancer Res 15: 6758-6762, 2009.

23. Peltenburg LT: Radiosensitivity of tumor cells. Oncogenesis and apoptosis. Q J Nucl Med 44: 355-364, 2000 